\title{
Seeing is Believing: New York Academy of Medicine's Vesalius 500th Year Celebrations
}

\author{
Brandy Schillace
}

Published online: 5 November 2014

(C) Springer Science+Business Media New York 2014

This year marks the 500 year anniversary of Andreas Vesalius' birth (né Andries van Wesel, 1514-1564), and celebrations in his honor are taking place across the globe.

Vesalius' groundbreaking De humani corporis fabrica (The Fabric of the Human Body) appeared first in 1543. Departing from more stylized and metaphorical observations of the body and, most importantly, challenging the work of Galen, Fabrica profoundly changed medical and anatomical knowledge. Unlike the second-century Greek physician Claudius Galenus, who based many of his anatomical observations on dissections of dogs, pigs, and monkeys, Vesalius had the benefit of opening human bodies and, with the help of artists, rendering them as he saw them. In the process, he ushered in a new emphasis on artistic realism that has persisted through the ages. And yet, this relationship between art and anatomy is not without problems; what counts as art? Who has the right to speak for the body? What, in fact, is realism-or truth-when it comes to anatomical representation?

These were the queries of the recent Festival of Medical History and the Arts at the New York Academy of Medicine, Vesalius 500: Art, Anatomy, and the Body (Oct 18, 2014). Engaging a group of scholars, physicians, artists, and performers, this one-day conference explored the legacy of Vesalius' work and it is continued influence on medicine - and even upon embodied identity. Guest-curated by artist and anatomist Riva Lehrer and hosted/co-curated by Lisa O'Sullivan (Director, Center for the History of Medicine and Public Health, NYAM) and Paul Theerman (Associate Director), the one-day conference included sessions on everything from wearable anatomy art to medical 3-D printing demonstrations. Heidi Latsky presented the "GIMP" dance project, Alice Dreger discussed the invention of medical photography, and others focused their attention on the Fabrica itself-from the metaphors of the Frontispiece to the issues of translation, duplications, and even plagiarism.

B. Schillace $(\square)$

Dittrick Medical History Center, Case Western Reserve University, Cleveland, USA

e-mail: Bls10@case.edu 
Through these presentations, Lehrer wanted to explore the idea of seen and seeing; when once we have a model perceived as perfect and "true" (part of the legacy of Vesalius' work), it changes perceptions of "normal" bodies. "What are we really seeing," asks Lehrer in her curator's statement, "and what do we believe we see?"

My contribution took up this question from the perspective of reproduction-not only human reproduction, but also the reproducibility of knowledge. In the eighteenth century, a dramatic shift occurred in birth practices, the implications of which shaped medical approaches to women for more than a century in the West. The female midwife, long the attendant to birthing women, is replaced by her male counterpart-a man-midwife, a doctor, a wielder of tools. In a space of decades, even the word "man-" is dropped by the eminent William Hunter, the anatomist and physician to Queen Charlotte. For him, in late eighteenth century England, midwives are necessarily men-while women are called "female practitioners" and frequently villainized as uneducated (and even decried as witches). The reasons for this shift are multiple and frequently debated. One thing remains fairly certain, however; from the hands of two men, both concerned with aspects of midwifery, come the best known anatomical atlases for pregnant anatomy. William Smellie's $A$ Sett of Anatomical Tables and Hunter's own Anatomia uteri humani gravidi (The Gravid Uterus) take the Vesalian imperative of fealty to realism further than any anatomists in the period. More importantly, they do so for the purpose of rendering the "real" female anatomy, naked of flesh, open to view, an object for observation. In Hunter's words, "the simple portrait in which the object is represented exactly as it was seen... carries the mark of truth and becomes almost as infallible as the object itself" (1774). In other words, the anatomy becomes the body-a replacement for use by students who will see only truth, rendered objectively. But of course, seeing is preceded by expectation; we construct as we see, bringing our separate contexts and experiences to bear. A look at the second atlas by W. Smellie makes this remarkably plain.

For Smellie, the tables were primarily about practice. Infants are represented in high detail, while the surrounding context is grayed out, unimportant. They look more like diagrams for use. Hunter's work, by contrast, reveals the mother as a body-dead and not living. Hunter's plates display the female form headless, with stumped legs, fat, and other material matter in full view. There has been speculation about the visceral impact of such renderings and whether they intended to be sensational, but I think a more interesting question is this: what were the aims of the two atlases? What did the anatomists want viewers to "see" and to "believe"? It is an especially important consideration, for despite the differences in presentation, both atlases were illustrated by the same artist, Jan van Rymsdyk (Fig. 1).

Many of the other anatomists from Vesalius to Gautier (also in the eighteenth century) displayed anatomized female bodies as living, smiling, with fresh faces and perfect hair. These models invited the viewer to inspect. Rymsdyk instead works to render, as Hunter puts it, "exactly" what he saw. But if he is influenced only by empirical evidence, then what explains the differences between the two anatomies? And why, in both, do the infants appear alive but sleeping? The differences are as much to do with the competing visions of the anatomists as the interests of the artist. Historian Lucy Inglis explained in a recent talk for the Dittrick Museum (Handerson 

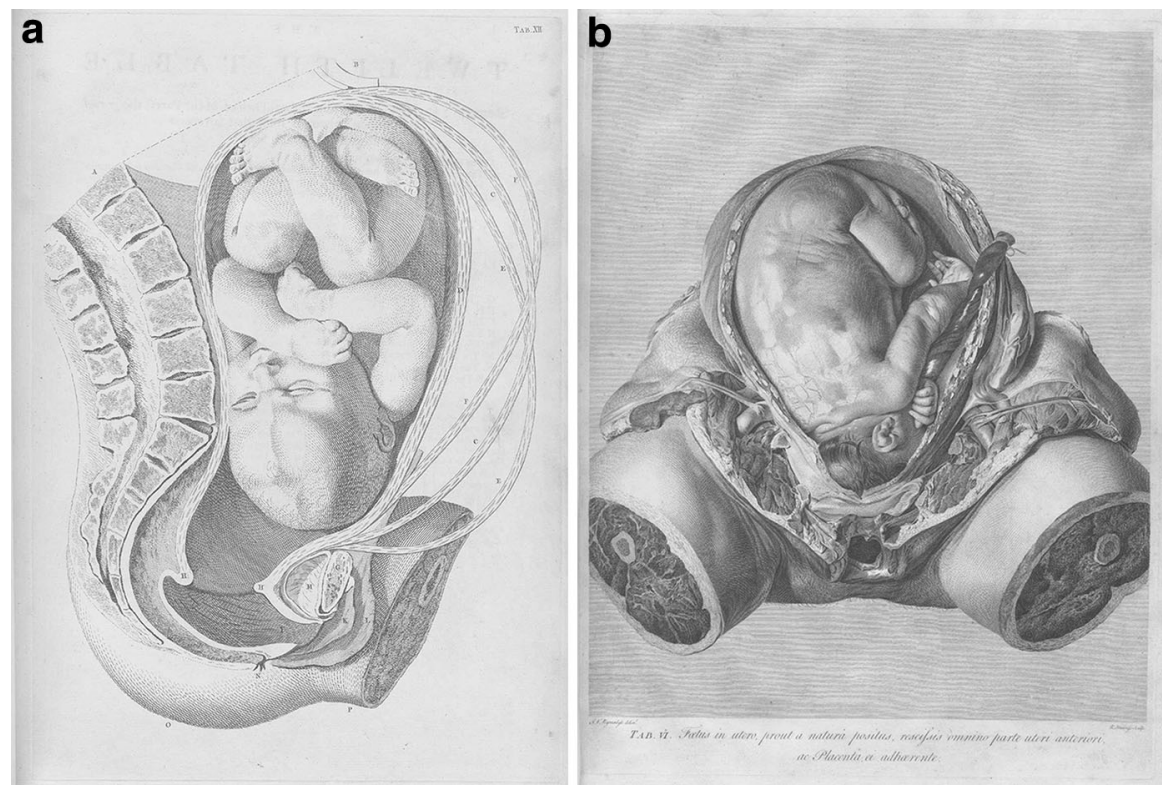

Fig. 1 a W. Smellie, care of Dittrick Medical History Center, Tab 12. b W. Hunter, care of Dittrick Medical History Center, Tab 6

Lecture, 2014) that in at least one case, a fetus was removed from one woman's womb and placed in another to create a more suitable drawing. (So much for being infallible truth.) Rymsdyk himself was deeply troubled by such things and Inglis notes that he ultimately leaves the atlases behind for work in Jamaica-returning only at the insistence of Hunter. What we "see" in the two works, then, represents the cornerstone of a profession on the rise-man-midwifery-as it attempts to render the "science" of the womb and the pathology of birth. A woman's "mysterious, messy, inefficient apparatus controlled and contained" (Schillace 2013), a sentiment about women's reproductive potential that would remain cogent well into the nineteenth and early twentieth century, wherein birth became a problem for medicine to "solve" through the means of chloroform, forceps, and other more questionable techniques.

What we "see" in the anatomical atlases - these mentioned above, but also the work of Vesalius and those who follow after him and in his footsteps-is the product of mediation and culture. It remains as true today as ever, whether we work in history museums like Eva Åhrén, who spoke at Vesalius 500 about the display of specimen bodies, or in medicine, sociology, or anthropology. The Fabrica's artistic display of the human body mediated what the curious anatomist, surgeon, physician, and even the public saw and believed about bodies. Today, we continue to take part in mediation, and in an ever expanding understanding of what it means to be human. 


\section{References}

Hunter, W.

1774 Anatomia uteri humani gravidi London, Birmingham. Journal Baskerville.

Schillace, B.

2013 'Reproducing' Custom: Mechanical Habits and Female Machines in Augustan Women's Education. Feminist Formations 25(1): 111. 